\title{
Filhos da sociedade de consumo: estratégias de diálogo com a criança-cliente
}

\section{Saraí Schmidt}

Doutora; Universidade Feevale

saraischmidt@feevale.br

\section{Carolina Rigo}

Mestranda; Universidade Feevale

carolahlah@gmail.com

\section{Resumo}

O trabalho coloca em pauta estratégias persuasivas que pensam e tratam a criança como público-alvo, considerando o imperativo do consumo atual. A proposta problematiza o processo de construção da mensagem publicitária em um tempo no qual as crianças tornaram-se filhas da chamada sociedade de consumo. A análise contempla três entrevistas com profissionais de agência de publicidade realizadas em 2012, e tem como arcabouço teórico as contribuições de Zygmunt Bauman (1999, 2001, 2008, 2009), Beatriz Sarlo (1997), Néstor García Canclini (2008) e Renato Ortiz (2007). A pesquisa evidencia um reconhecimento da soberania da criança por parte do mercado, uma vez que a comunicação está ajustada e direcionada ao público infantil. Deste modo, as práticas consolidadas no exercício publicitário se encarregam de aproximar crianças e adultos enquanto clientes. Portanto, este estudo crê na responsabilidade que as agências de publicidade e seus profissionais têm em relação aos efeitos publicitários orientados à constituição das identidades e à cultura infantil. Deste modo, faz-se necessária a ampla discussão do assunto aqui proposto.

\section{Palavras-chave}

Mídia. Consumo. Criança. Publicidade. 


\section{Introdução}

Este trabalho analisa a relação da mídia com a cultura infantil. Tomando como ponto de partida as contribuições de Zygmunt Bauman (1999, 2001, 2008, 2009), Beatriz Sarlo (1997), Néstor García Canclini (2008) e Renato Ortiz (2007), a pesquisa articula discussões dos campos da comunicação, consumo e cultura e coloca em pauta a relação entre publicidade e criança. 0 estudo analisa o processo de construção da mensagem publicitária - que pensa e trata a criança como público-alvo -, a fim de problematizar a potência e a responsabilidade da publicidade na constituição de uma cultura infantil/de identidades infantis, uma vez que não podemos mais desassociar infância e práticas de consumo. Vivemos em um tempo no qual as crianças tornaram-se filhas da sociedade de consumo. Este artigo integra uma pesquisa mais ampla, que tem como objetivo central problematizar os ensinamentos da mídia sobre a infância, estabelecendo uma política cultural que demarca o que significa ser criança na contemporaneidade.

O objeto de análise contempla três entrevistas realizadas com profissionais de agência de publicidade, os quais atuam na área de planejamento e possuem ampla experiência no atendimento de empresas que fabricam ou vendem produtos infantis. As entrevistas foram realizadas em junho de 2012, sendo que no período dois dos entrevistados atuavam em empresas de Porto Alegre e um no Rio de Janeiro. 0 foco das entrevistas foi direcionado à compreensão dos processos de trabalho quando envolvem produtos para crianças, assim como o ponto de vista dos profissionais acerca da sua própria atividade. A prática publicitária que abrange pesquisa de comportamento do consumidor, estratégia de conteúdo e de mídia, pré-teste de campanha, entre outras técnicas que aumentam a eficácia da mensagem para o consumo, aponta para um tratamento muito semelhante dado ao público infantil em comparação ao que é dado aos jovens e aos adultos.

\section{Consumo como vocação}

O consumo tornou-se uma marca identitária do nosso tempo e ocupa lugar central na estruturação do indivíduo e das relações humanas. Distinto da exaltação do trabalho e da busca da atividade a que cada sujeito foi predestinado, Bauman (2008) aponta o consumo como vocação do homem na sociedade atual, refratando esse conceito para o consumismo. Fala-se em vocação porque ser consumidor é papel do indivíduo na contemporaneidade e porque essa prática trata de performance e de nos aperfeiçoarmos a partir de cada nova 
compra, sendo que "[...] a competência mais necessária em nosso mundo de fins ostensivamente infinitos é a de quem vai às compras hábil e infatigavelmente". (BAUMAN, 2001 p. 88). Esse é seu destino e seu propósito, quando são pelas relações de consumo que o indivíduo pode compreender a si mesmo e constituir sua identidade.

O consumo tem movimento garantido na insaciabilidade de desejos e vontades. A estagnação é condenável e sentir-se realizado e satisfeito com o que se tem ou com o que se é - sem precisar de novos começos, de novos produtos, de novas identidades - não faz parte das crenças da sociedade do consumo. 0 descarte traz a sensação de bem-estar e de estar "evoluindo", uma vez que se joga fora o antigo e desajustado por um artigo novo. 0 desconhecido que está por vir, em substituição, é uma nova oportunidade de ser feliz (mesmo que momentânea). Nas palavras de Bauman (2008, p. 50), “Na vida 'agorista' dos cidadãos da era consumista o motivo da pressa é, em parte, o impulso de adquirir e juntar. Mas o motivo mais premente que torna a pressa de fato imperativa é a necessidade de descartar e substituir". O propósito do consumismo éevitar estar satisfeito, porque só a insatisfação assegura a continuidade da sociedade dos consumidores.

Os meios técnicos de comunicação facilitam a circulação das narrativas e das imagens dos artigos simbólicos. Contudo, aqueles que não têm poder de compra admiram com olhos desejosos os afortunados e ditos "bem sucedidos", que podem adquirir os objetos estampados em telas, impressos e outdoors. Esse fator, segundo Sarlo (1997, p. 107) parece ser a razão da distinção promovida pelos objetos quando “[...] todos os desejos tendem a assemelhar-se, mas nem todos os desejos têm as mesmas condições de realizarem-se. A ideologia nos constitui em consumidores universais, embora milhões sejam apenas consumidores imaginários".

0 padrão cultural consumista mostra-se, em vista disso, um tanto persuasivo especialmente em relação às crianças que possuem poder de julgamento e discernimento ainda em construção -, uma vez que são significativamente díspares as condições para sua prática. Mesmo assim, o discurso mercadológico fomenta a ideia de que o sujeito é livre para escolher entre os milhões de produtos disponíveis nas prateleiras dos supermercados e shoppingcenters, e que a competência de adquiri-los é uma questão de empenho individual. Sarlo (1997) e García Canclini (2008) indicam que tal discurso, de preceito democrático, é ilusório. É a racionalidade econômica, ao classificar as mercadorias em níveis bastante definidos de maior e menor valor - diferenciando da mesma forma seus usuários -, que 
primeiramente define quem consome o quê, criando estilos de vida e representações para cada estilo.

Essa segmentação imaginada não se mantém restrita quando os objetos atingem o mercado. Nos meios de comunicação de massa, nas mídias digitais e redes sociais e nas próprias lojas onde circulam milhares de consumidores, entre os quais crianças, os limites previamente pensados são transpostos e os sujeitos são impactados por toda sorte de bens. Como observa Sarlo:

[...] os programas para adolescentes são vistos por crianças e adultos; [...] e, basicamente, os anúncios comerciais da programação do dia ou da semana podem ser vistos a qualquer hora e põe em circulação, diante de públicos não específicos, imagens específicas. (SARLO, 1997, p. 80).

Inferimos, desse modo, que o universo infantil é interpelado tanto por apelos consumistas destinados a eles como por aqueles que focalizam jovens e adultos. Esse conteúdo comunicacional está baseado em representações que contribuem na construção da identidade infantil contemporânea, como veremos adiante, ao discutir as reflexões dos entrevistados neste estudo.

Nesse contexto, talvez seja mais pela influência da mídia e seus artefatos do que pela família e escola que, atualmente, os pequenos descobrem preferências materiais e aprendem características e atitudes de pessoas a quem se espelhar - muitas delas são celebridades do entretenimento e da indústria cultural. Afinal, pais estão no trabalho, em jornada a cada ano mais longa, visando ter mais conforto ou condições financeiras, para comprar bens materiais que seus filhos ou eles próprios necessitam, uma vez estimulados pelo "bombardeio contínuo de anúncios". Cria-se uma lógica de compensação material pela ausência do lar, ou seja, aquilo que Bauman (2008, p. 153) cita como ciclo de "materialização do amor". E no momento em que produtos, publicidade e corporações extrapolam a esfera econômica e entram nos campos ditos educativos, familiares ou de socialização, torna-se comum qualificar o acesso ao consumo como forma de vida total.

A publicidade, na sociedade do consumo, é uma importante fonte produtora de sentidos, que fomenta determinadas alianças identitárias. Acerca das identidades contemporâneas, entendemos que é no mercado que "[...] os homens exercem suas individualidades". (ORTIZ, 2007, p. 161). A supremacia do objeto provocou a mistura entre o mercado e os consumidores, uma vez que o objetivo final do consumo é também produzir um indivíduo sedutor e vendável. A identidade torna-se uma amálgama entre aquele que 
consome e o que é consumido, formada pela circulação incessante de bens simbólicos que cada indivíduo escolhe para vender, comprar ou descartar. Bauman assegura que,

[...] na sociedade de consumidores, ninguém pode se tornar sujeito sem primeiro virar mercadoria, e ninguém pode manter segura sua subjetividade sem reanimar, ressuscitar e recarregar de maneira perpétua as capacidades esperadas e exigidas de uma mercadoria vendável. (BAUMAN, 2008, p. 20).

Isso significa cultivar o eterno ciclo de compra e descarte, substituindo não apenas os objetos, mas o sentimento de frustração pela possibilidade de satisfação. A frustração que, como visto, pode ser resultado do desequilíbrio nos processos de produção e acesso aos bens, aparece ainda na aquisição do objeto que acaba por não satisfazer o indivíduo tal como prometido e idealizado. Assim, o sujeito precisa ir à busca de outro bem simbólico, que prometa uma vida mais feliz. Fórmulas variadas para conquistar a felicidade nos cercam por todos os lados - nos livros, nos meios de comunicação, nas palavras de especialistas, por meio da saúde, de uma vida equilibrada, pela prática da solidariedade ou pela realização profissional - e nos lembram, a cada dia, dessa tarefa preponderante dos tempos atuais. Sarlo (1997) utiliza o termo "colecionador às avessas" para explicar a alta rotação de artigos, no qual o valor não está no bem adquirido, mas no ato da compra, depositando a cura da infelicidade na sociedade de consumo, muitas vezes gerada por ela mesma, no eterno ato de consumir.

Se o movimento de bens fundamenta a economia consumista no binômio excessodesperdício e, mais importante, estabelece uma ordem social, como não problematizar a vulnerabilidade do público infantil inserido nessa lógica estruturante da sociedade, sobretudo quando Bauman (2008, p. 65) sinaliza o consumismo como um novo tipo de economia - a do engano -, pois “[...] aposta na irracionalidade dos consumidores, e não em suas estimativas sóbrias e bem informadas; estimula emoções consumistas e não cultiva a razão". É importante nesse momento ponderar sobre a diferença entre consumo e consumismo. Enquanto o primeiro conceito, para Bauman (2008), habita a esfera da satisfação de necessidades, o segundo está na ordem do excesso, da velocidade e do desperdício que orienta a existência e o convívio humano. 0 consumismo caracteriza-se como a capacidade de relacionar felicidade ao volume de desejos saciados, que são substituídos imediatamente após serem atendidos. Para o sociólogo, portanto, a irracionalidade é colocada na perspectiva da insaciabilidade e desta como um atributo da sociedade, particularmente em comparação a formas de vida precedentes. 
Já García Canclini (2008) utiliza-se de outra perspectiva para discutir os significados do consumo em nosso tempo. Ele parte de um campo integrador, no qual os indivíduos teriam consciência dos valores simbólicos que os artigos mercantis carregam e, conscientemente, formariam grupos socais a partir disso. 0 consumo seria uma atividade sociopolítica reflexiva porque abrange interação, classificação, conflitos e distinções. 0 autor discute a questão da segmentação dos grupos e da distinção promovida pelos bens de consumo. Para ele, o consumo serve para pensar no momento em que decidimos o que é valioso, no qual escolhemos como queremos nos diferenciar e em como nos integrar.

Considerando as discussões aqui apresentadas, é preciso lembrar das articulações estratégicas e criativas usadas pelo marketing e pela publicidade, a fim de criar campanhas atraentes para impactar o consumidor imaginado e que recorrentemente pode ser uma criança. A mercantilização vem adentrando o mundo infantil - um universo de entretenimento e povoado por brincadeiras, jogos, histórias e personagens. Na sociedade de consumo, jogos ganham cartões de crédito e produtos financeiros, histórias são interrompidas por anúncios e merchandisings, bonecos e personagens são adornados por objetos de luxo e estampados em toda sorte de bens materiais. A brincadeira torna-se o comprar. Ademais, a imaginação da criança que se fazia passar por adulto - vestindo roupas, sapatos e acessórios dos pais -, vêm se mostrando realidade.

Empresas atendem os desejos infantis colocando no mercado artigos adultizados, tais como maquiagens e sapatos de salto, representando as crianças em situações amadurecidas. Nas palavras de Bauman (2008, p. 73), "Nessa sociedade, o consumo visto e tratado como vocação é ao mesmo tempo um direito e um dever humano universal, que não conhece exceção". Esta vocação para o consumo está diretamente conectada com as questões do entretenimento infantil individualizado do nosso tempo (internet, games, televisão), quando já não mais precisamos do amigo, do colega, do humano para a diversão. Neste tempo de "vocação para o consumo" ou do "consumo como direito e dever universal", o entretenimento das crianças é um espaço público disputado, onde diferentes interesses sociais, econômicos e políticos competem pelo controle.

\section{Criança-cliente}

Para colocar em discussão a potência da publicidade na constituição da cultura infantil, quando se torna difícil desassociar infância e práticas de consumo, é importante analisar o processo de construção do discurso publicitário - com seus atributos prioritários 
de sedução e velocidade. Este estudo focaliza as etapas primeiras dessa prática profissional, que envolvem pesquisa de comportamento do consumidor e definição de estratégia de conteúdo. Atividades usualmente gerenciadas por planejadores nas agências de publicidade.

Ao serem indagados sobre semelhanças e diferenças na abordagem entre os públicos adulto, jovem e infantil para o processo de trabalho, os entrevistados apontam:

É um público com idade bem complicada de extrair informação. Então, grande parte do grupo virou uma série de dinâmicas diferentes, de recorte e colagem, de brincar, de contar histórias, mas muito no sentido de tentar entender o que essas crianças curtiam no dia a dia delas, de tentar caracterizar o que eram as coisas legais e o que não era legal. (Entrevistado C).

Confesso que não tem muita diferença, não. Preciso entender o target: mulher, velho, criança, homem, gay... vou desenvolver uma metodologia pra entender esse cara; vou olhar a categoria, vou olhar o que está sendo comunicado e propor minhas estratégias. (Entrevistado A).

Tem um nível de detalhamento com um trabalho de criança que a gente não tem pra outros trabalhos. São cuidados porque é uma fase que muda muito, muito rápido, tu trabalhar a criança de cinco anos é muito diferente de trabalhar a de sete. (Entrevistado B).

As únicas discussões de tratar diferente mesmo, é no sentido de buscar um formato de comunicação mais eficiente. Então a gente já fez coisas de levar a criação pra um parquinho de diversões e ter uma criança pra cada criativo pra que eles conversem, brinquem junto e entendam melhor a forma de pensar, a linguagem e tudo mais. (Entrevistado B).

Embora a pesquisa de mercado esteja sempre a serviço de compreender hábitos, linguagem, modismos e particularidades de gênero que ajudarão a desenvolver uma comunicação mais persuasiva para o ato da compra, os métodos utilizados para a pesquisa mercadológica com crianças podem diferir dos praticados com adultos, uma vez que os profissionais consideram as particularidades dos estágios de desenvolvimento humano. Percebemos, portanto, que se estabelece um diálogo com as crianças antecedente à produção da comunicação mercadológica, que visa entender essa quase "outra língua". Os publicitários partem do cotidiano das crianças, visando encontrar signos que geram identificação e que facilitam a decodificação da mensagem publicitária pelo público-alvo quando transmitida posteriormente. Nesse sentido, a pesquisa com consumidor serve para orientar a leitura do texto. É estabelecido neste momento um diálogo assimétrico, no qual a criança torna-se o emissor e se revela para compreensão do receptor. Conforme Cook há um reconhecimento por parte do mercado da soberania da criança, que ajusta sua comunicação do ponto de vista dela: 
0 'direito' das crianças a consumir precede e prefigura de várias maneiras e outros direitos legalmente constituídos. As crianças ganharam uma 'voz' na seção de vendas a varejo, nos concursos de 'faça-você-mesmo e dê um nome', na escolha de roupas e nos planos dos pesquisadores de mercado décadas antes de seus direitos serem declarados em contextos como a Convenção das Nações Unidas sobre os Direitos da Criança em 1989. (COOK, 20041 apud BAUMAN, 2008, p. 83).

Ao descrever o processo de desenvolvimento de uma campanha na qual participou em 2008 e 2009, o entrevistado A comenta que havia dois produtos de uma indústria de alimentos a serem divulgados pela agência onde trabalhava - um focado em crianças de 0 a 4 anos e outro em crianças de 9 a 12 anos (chamados tweens). Interessante observar que, segundo esse publicitário, as decisões dos profissionais acerca de que estratégias de comunicação adotar foram: 1) dialogar com as mães das crianças menores, que por serem pequenas demais não compreenderiam a mensagem publicitária: "a gente não tem como falar com uma criança de 1 ano, de meses, de 2 anos. (...)o target primário ali era a mãe"; 2) dialogar com os próprios tweens, visto que nessa idade "é um cara que já decide o que vai comer, as marcas... então a gente falava com ele".

Já em relação a outro trabalho - feito também para uma indústria de alimentos -, a iniciativa tomada foi a de desenvolver uma comunicação que gerasse, para as mães, orientação alimentar, pois foi diagnosticada na pesquisa a carência de conhecimento dos pais sobre o assunto. Conforme a entrevistada B, esse é um caminho que traria benefícios, uma vez que a comunicação almejaria ajudar "as mães a fazerem as crianças comerem comida mesmo, não lanche, porque tornaria esse momento da refeição mais lúdico". Na visão do planejador, esses trabalhos são os mais bonitos de se fazer, porque tentam "trazer uma conscientização", buscam "trabalhar de uma forma mais correta". Mesmo assim, ele aponta para o fato de que a maioria dos trabalhos que envolvem produtos infantis é "realmente apelativo, para despertar o desejo; usar as crianças, na verdade, como grandes incentivadoras".

Do segmento de vestuário, narrou o entrevistado C, uma dada empresa tem estratégia já previamente estabelecida para se comunicar com o público infantil, bem diferente das adotadas quando o consumidor é jovem ou adulto. Os produtos infantis estão fora do core business da empesa e, por isso, o foco é a venda em curto prazo com pouca preocupação em construção de imagem de marca. Essa visão do negócio orienta a agência a falar diretamente com as crianças utilizando-se de "uma estratégia triangular bem reta", brindes: "eu compro

\footnotetext{
${ }^{1}$ COOK, D. T. The commodification of childhood: the children's clothing industry and the rise of the child consumer. Durham: Duke University Press, 2004.
} 
brindes, eu faço as crianças quererem esses brindes e elas têm que pedir esses brindes pra mãe". A estratégia adotada não é a recomendada pela agência, afirma o planejador, porém, é utilizada mais por visão estratégica do que ética, uma vez que sua preocupação é com o que a mãe da criança pode pensar sobre essa atitude da marca.

Interessa-nos verificar a produção estratégica da mensagem e de como certas atividades e pensamentos são pouco contestados eticamente por já fazerem parte da prática da profissão ou do mundo dos negócios. Tarefas institucionalizadas e, portanto, vistas como "padrão", as quais reproduzem a narrativa estruturante da sociedade de consumo. Não é o pensamento crítico ou moral, mas são as condições externas (leis, mídia e oportunidades de mercado) que fomentam posturas mais ou menos apelativas das empresas e das agências, quando em relação aos produtos e à comunicação com crianças. Ademais, os exemplos citados evidenciam o pensamento de Sarlo (1997) e de García Canclini (2008), que afirmam ser o mercado - as grandes estruturas de administração do capital -, o primeiro a definir quem consome o quê. Por conseguinte, essas histórias e caminhos analíticos nos motivam a refletir sobre a liberdade do consumidor e sobre quais devem ser os limites do mercado em geral e da publicidade em particular. As práticas e decisões na publicidade estão intimamente associadas com o seu contexto social, o tempo vivido, as políticas de regulamentação, "[...] já que é [a publicidade] ao mesmo tempo uma instituição econômica de produção cultural, um sistema comercial e mágico, uma indústria e uma forma de arte". (PIEDRAS, 2005², p. 67 apud PIEDRAS; JACKS, 2006, p.11).

Os exemplos anteriormente descritos permitem a análise do processo comunicativo publicitário e a confirmação empírica de que a prática dessa atividade articula produtos e universos simbólicos com a vida cotidiana em uma constante relação de influência mútua: de um lado bebe-se da fonte da dita realidade social, das atitudes e dos pensamentos do consumidor; e de outro, o produto final da agência - campanha publicitária - influencia o consumo. As regulamentações, vistas como os principais limitadores do incentivo ao consumo de bens simbólicos, não incidem nesta etapa de pesquisa do consumidor, ou seja, na etapa de produção de conhecimento sobre o universo infantil, que abastece os profissionais da comunicação de argumentos de venda.

As marcas olham o comportamento, claro, elas estão olhando as pautas das pessoas, quais são as angústias que a gente pode resolver, né, e aí a própria criação do MC Lanche Feliz é um ótimo exemplo porque se deram conta

\footnotetext{
2 PIEDRAS, Elisa. A articulação da publicidade com o mundo social: a constituição do fluxo publicitário nas práticas de produção e de recepção. 2005. Dissertação (Mestrado em Comunicação e Informação) - Programa de Pós-graduação em Comunicação e Informação, Universidade Federal do Rio Grande do Sul, porto Alegre, 2005.
} 
que os pais passam cada vez menos tempo com as crianças e dentro disso estão os poucos momentos em que eles estariam juntos seriam momentos premiados, onde a criança ainda ganha um brinquedo. (Entrevistado B).

O ciclo criado entre vida social e representações desta em produtos midiáticos, que acabam por influenciar o imaginário infantil, nos ajuda a analisar o papel que outras relações sociais, especialmente as amizades, no caso das crianças, têm para a constituição da subjetividade e de como a proibição da publicidade, sozinha, - no sentido de que outras medidas referentes à ordem social consumista estabelecida não seriam tomadas - não traria benefícios majoritários em um curto período ou não resolveria o fenômeno do consumismo infantil. "As ideias que se propagam e por isso a publicidade não tem como mudar tudo sozinha”, afirma o entrevistado B, e complementa, "[...] porque têm vários outros tipos de propaganda que não é a oficial... o colégio vai existir, a convivência com outras crianças, a convivência com outros adultos. Seria bem mais fácil se a gente só parasse a propaganda e as coisas funcionassem, né?". Não se trata, evidentemente, de questão de fácil resolução. A publicidade não é culpada, nem inocente. Ela é uma entre várias fontes produtoras de sentido e, por isso, é, também, responsável pela constituição de identidades e de imaginários. Tal perspectiva aparece na voz do mesmo entrevistado, momentos posteriores, quando ele afirma:

Essa postura de tratar a criança não como criança, ela não é só da propaganda, ela é dos próprios pais. Eu tendo a acreditar que podem proibir e eu acho que ajuda não tendo o apelo, porque as crianças ficam realmente vidradas e pedindo tudo que elas veem pela frente, né. Mas eu não acredito num movimento isolado assim... Acho que muitas coisas deveriam acontecer, deveriam ter muito mais proibições pra crianças, porque eu acho que se não proibir não é por pura conscientização que as coisas vão mudar.

As análises dos depoimentos coletados no estudo nos levam a questionamentos acerca da responsabilidade da agência e de seus profissionais sobre os efeitos da publicidade na constituição das identidades e da cultura infantil. As relações de persuasão publicitária frente à criança ainda precisam ser amplamente discutidas, para estabelecer limites éticos e colocar no centro do debate os compromissos dos diferentes agentes envolvidos no processo de oferta e consumo de bens simbólicos. Muitas vezes, o mercado publicitário argumenta que está simplesmente cumprindo com o seu papel de alavancar as vendas do cliente. Pela lógica do discurso dos profissionais sobre si, a responsabilidade de estabelecer um limite é exclusivamente da família, corroborando com as discussões de Bauman (1999) referentes à privatização das responsabilidades. É função individual dos pais frear os 
impulsos consumistas de seus filhos, assim como é deles o fracasso de não conseguir. Afinal, cada um é livre para optar entre comprar ou não comprar. 0 autor lembra que a privatização de assuntos coletivos promove a não autocrítica ou a não crítica social e sistêmica; consequentemente culpa e negligência, ainda que interligadas às questões coletivas, deslocam-se para a esfera privada.

Desse modo, talvez possamos pensar que a solução para a "síndrome do consumo" não residiria simplesmente em estabelecer uma fiscalização mais efetiva na regulamentação publicitária. Talvez seja possível ampliar este debate ouvindo diferentes vozes. Nas palavras do entrevistado B, "existe um padrão errado também de pensamento de uma sociedade doente em vários sentidos". Por essas razões é que a solução não está em achar culpados, mas em refletir acerca das responsabilidades, das necessidades, das consequências e dos limites na publicidade infantil. É viável estabelecer tais limites ou o bom funcionamento econômico deve prevalecer? Para o planejador A, "as pessoas não vão deixar de consumir por ter um pensamento mais saudável, um pensamento mais correto sobre hábitos" e restrições à publicidade para público infantil trariam benefícios sociais "porque a criança não tem as armas que um adulto tem. Está se criando um desejo, uma necessidade que aquela criança não tinha”. Desejo este que não será satisfeito com a mercadoria comprada, nem compensará a eventual ausência familiar, típica dos tempos atuais. Por fim,

\footnotetext{
Do ponto de vista social, acho que a gente (publicidade) não aumentaria conflitos familiares que talvez já existam - da criança querer uma coisa, os pais, outra. Acho que o elemento anunciante acaba, muitas vezes, intensificando alguns desses conflitos por aumentar o estímulo, aumentar o desejo ou até gerar o desejo de algo que vai ser mais um conflito, mais uma coisa a ser debatida entre mãe e criança. Então acho que a mudança de falar com a mãe e a mãe ser o filtro e tu convencer ou não ela, já seria uma mudança... fala com quem tem o controle da família e deve ter. (Entrevistado C).
}

Embora o contexto seja complexo e a responsabilidade partilhada, parece que ainda falta aprimorar a postura das agências de publicidade e de seus profissionais. Ponderando os argumentos levantados pelos próprios publicitários, refletimos ser possível realizar uma publicidade mais ética, mas essa tarefa ainda é um desafio. A fim de reduzir riscos e perdas de faturamento, a maioria das empresas e das pessoas se coloca em uma posição que segue a zona de conforto, ou seja, acabam por continuar fazendo o que já fazem ou o que todo mundo faz, e dessa forma, se retroalimenta a narrativa e a lógica da sociedade de consumo. 


\section{Considerações finais}

A partir das discussões de Bauman (1999, 2001, 2008, 2009), Sarlo (1997), García Canclini (2008) e Ortiz (2007), e analisando o depoimento dos publicitários entrevistados, nosso estudo se propôs a uma reflexão acerca da responsabilidade e dos limites a serem estabelecidos para a atividade de publicidade que hoje atua livremente na constituição da cultura infantil. 0 texto aposta na ideia de que vivemos em um tempo no qual as crianças tornaram-se filhas da sociedade de consumo, devido ao estreito vínculo dos bens simbólicos, em geral, e da mensagem publicitária, em particular, com o mundo social, uma vez que os bens se converteram em potentes agentes de representação, produção e circulação de signos, às vezes tão ou mais eficazes que as tradicionais instituições sociais (família, escola, igreja).

Entendemos que o debate sobre a "educação vitalícia para o consumo", expressa por Bauman (2008), merece alcançar os publicitários para que eles lancem um novo olhar ao se direcionarem às crianças. Afinal, são eles que estão estabelecendo diálogos cada vez mais longos e mais persuasivos com os pequenos. Há um método de trabalho publicitário aparentemente já consolidado que iguala crianças e adultos enquanto clientes em variadas etapas de um processo de comunicação. A análise aqui empreendida aponta que tal tratamento deve ser ininterruptamente discutido.

\section{Referências}

BAUMAN, Zygmunt. A arte da vida. Rio de Janeiro: Zahar, 2009.

BAUMAN, Zygmunt. Modernidade líquida. Rio de Janeiro: Zahar, 2001.

BAUMAN, Zygmunt. Modernidade e ambivalência. Rio de Janeiro: Jorge Zahar, 1999.

BAUMAN, Zygmunt. Vida para consumo: a transformação das pessoas em mercadoria. Rio de Janeiro: Zahar, 2008.

GARCÍA CANCLINI, Néstor. Consumidores e cidadãos. 7. ed. Rio de Janeiro: UFRJ, 2008.

ORTIZ, Renato. Mundialização e cultura. São Paulo: Brasiliense, 2007.

PIEDRAS, Elisa Reinhardt; JACKS, Nilda. A contribuição dos estudos culturais para a abordagem da publicidade: processos de comunicação persuasiva e as noções "articulação" e "fluxo". Revista E-compós, Rio de Janeiro, v. 6, p. 2-16, ago. 2006. 
SARLO, Beatriz. Cenas da vida pós-moderna. Rio de Janeiro: Editora da UFRJ, 1997.

\title{
Children of the consumption society: strategies of dialogue with the customer child
}

\begin{abstract}
This paper analyzes the process of advertisement construction and the constitution of contemporary child identities, in a time in which children have become closely related to the consumption society. The analysis comprises three interviews with professionals working in advertising agencies. Considering contributions by Zygmunt Bauman (1999, 2001, 2008, 2009), Beatriz Sarlo (1997), Néstor García Canclini (2008) and Renato Ortiz (2007) as starting points, the study problematizes teachings provided by the media about childhood, which establish a cultural policy that has delineated what means to be a child in contemporaneity. The paper addresses the limits of persuasive strategies that have thought and treated children as a target market, in a time when consumption has become an imperative.
\end{abstract}

\section{Keywords}

Media. Consumption. Child. Advertising.

Recebido em: 09/05/2014

Aceito em: 04/03/2015 